\title{
Climate hazards and health in Asia
}

Ilan Kelman

Institute for Risk \& Disaster Reduction and Institute for Global Health, University College London, England and Norwegian Institute for International Affairs, Oslo, Norway

Tim Colbourn

Institute for Global Health, University College London, England

\section{Notes on Contributors}

Ilan Kelman http://www.ilankelman.org is a Reader in Risk, Resilience and Global Health at University College London, England. Ilan's overall research interest is linking disasters and health, including the integration of climate change into disaster research and health research. I have three main areas: (i) disaster diplomacy and health diplomacy http://www.disasterdiplomacy.org ; (ii) island sustainability involving safe and healthy communities in isolated locations http://www.islandvulnerability.org ; and (iii) risk education for health and disasters http://www.riskred.org

Tim Colbourn is a Lecturer in Global Health Epidemiology and Evaluation at University College London, England. Tim works mainly on maternal, newborn and child health interventions in Africa and Asia. Tim also has research interests related to climate change and health, being most recently involved in the second Lancet Commission on Climate Change and Health. 


\section{Abstract}

Health challenges and climate hazards intersect in numerous ways in Asia, with human health exemplifying the vulnerabilities of individuals. Individual health directly influences casualties in floods; typhoons can exacerbate incidences of diseases already existing in a location, usually affecting those who are already most vulnerable; and droughts can do the same, augmenting infections and parasites. Environmental health is also affected by climate hazards, from crops and livestock suffering from drought or floods through to urban pollution worsening in heat waves and sandstorms.

Across Asia, climate change as one hazard driver amongst many seems likely to increase zoonotic disease and temperature-related health effects, but it might have mixed health impacts with respect to other climate hazards. For example, tropical cyclone frequency might decrease while severity increases. The most poignant health impacts of climate change might ultimately be on mental health, such as through traditional knowledge becoming outdated or the effects of being forced to move from one's home.

This chapter draws on examples from around Asia to provide an overview of the interaction of climate hazards and health, including environmental health and human physical and psychological health. First, definitions and scoping are given. Then, based on examples from Asia, the intersection of climate change, climate hazards, vulnerability, and health challenges is described, with climate change being placed in wider contexts. Finally, salient challenges for Asia are discussed in order to suggest a prioritised agenda for research and action.

\section{Introduction}

The largest and most populous continent, Asia, presents prominent challenges with respect to climate and health. While death tolls are notoriously unreliable and exact figures 
can be difficult to provide, some of the highest-fatality river floods have occurred in China killing millions (Cai et al., 2001) while some of the highest-fatality storm surges (killing hundreds of thousands) and tornadoes (killing hundreds) have been in Bangladesh (Chowdhury et al., 1993; Paul, 1998). The Himalayas experience deadly glacial lake outburst floods (Jain et al., 2012). Many of the low-lying atolls threatened by climate change lie in Asia, including Kiribati, the Maldives, the Marshall Islands, and Tuvalu (IPCC, 2013-2014).

Given the past history, the present situation, and the future challenges and opportunities, examining climate hazards and health for Asia is important for bringing focus to a continent with major difficulties in this realm—but also with plenty to offer and to teach the world about addressing the challenges and creating opportunities. The latter can never be overemphasised due to the importance of learning from and exchanging with everyone, rather than assuming that certain groups inevitably need assistance from other groups.

Communities facing the water-related health consequences of melting glaciers in the Andes can exchange knowledge with those in the Himalayas. The low-lying main cities of Barbados, the Bahamas, and Bermuda can share with places in the Pacific ideas and strategies about the psychological impacts of migration. Indian and Australian farmers can be tackling similar environmental health challenges during drought. This chapter describes some of these health and climate topics for Asia, important for the continent's future sustainability.

The IPCC (2013-2014: 5) defines climate as:

'the average weather, or more rigorously, as the statistical description in terms of the mean and variability of relevant quantities over a period of time ranging from months to thousands or millions of years. The classical period for averaging these variables is 30 years, as defined by the World Meteorological Organization. The relevant quantities are most often surface variables such as temperature, precipitation, and 
wind. Climate in a wider sense is the state, including a statistical description, of the climate system.'

From this definition, climate hazards are phenomena, trends, or processes related to the climate, hence related to the atmosphere, which have the potential for interacting with human vulnerability to lead to a disaster. Examples are cold temperatures, droughts, floods, fog, hot temperatures, lightning, rain, sleet, snow, storm surges, tornadoes, tropical cyclones, and wind. Some climate hazards have links beyond climate and the atmosphere, such as avalanches, glacial surges, landslides, rockslides, and wildfires. Processes which drive many of these hazards - at times worsening them but sometimes reducing their intensity, frequency, or magnitude-include climate change, climate variabilities, and climate cycles such as the El Niño-Southern Oscillation and the Pacific Decadal Oscillation.

WHO (1946) defines 'Health is a state of complete physical, mental and social wellbeing and not merely the absence of disease or infirmity'. One implication is that 'health' refers to individual human beings and WHO (1946) does state 'health is one of the fundamental rights of every human being'. The definition's ethos, though, applies to communities as well as to the environment. While recognising that no community is homogenous (Walmsley, 2006), community health indicators exist, such as in Sri Lanka (Jayasekara and Schultz, 2007), that could be applied elsewhere in Asia, after contextualising them.

Additionally, WHO (2015, online) defines 'Environmental health addresses all the physical, chemical, and biological factors external to a person, and all the related factors impacting behaviours. It encompasses the assessment and control of those environmental factors that can potentially affect health. It is targeted towards preventing disease and creating health-supportive environments.' The impetus is on a healthy environment for a 
healthy society and vice versa, but the implication is ecosystem health within the context of ecosystems being part of a wider environment that helps to prevent disease and to support human and community health.

For examining climate and health, this book focuses on Asia. Examples throughout range from the Middle East and eastern Turkey through the Arabian peninsula and the Hindu Kush-Himalayan Region to the Far East as well as from the Russian Arctic to the islands of Asian waters. The latter include Singapore, Indonesia, the Philippines, Japan and small islands states such as the Marshall Islands, Nauru, Timor-Leste, and Tuvalu. The next section describes climate change and its impacts on climate hazards, after which comes a section explaining how vulnerability causes health outcomes more than these hazards. Further case studies are provided in the following section to indicate the hazard-vulnerability balance. Then, the conclusion provides a proposed agenda for research and action.

\section{Climate Change Affecting Hazards in Asia}

\section{Defining and scoping climate change}

Contemporary climate change has two official definitions, one from science and one from policy. The main international scientific body responsible for assessing and synthesising climate change science is the Intergovernmental Panel on Climate Change (IPCC). IPCC (2013-2014: 5) states:

Climate change refers to a change in the state of the climate that can be identified (e.g., by using statistical tests) by changes in the mean and/or the variability of its properties, and that persists for an extended period, typically decades or longer. Climate change may be due to natural internal processes or external forcings such as modulations of the 
solar cycles, volcanic eruptions, and persistent anthropogenic changes in the composition of the atmosphere or in land use.

On the policy side, the main UN process for addressing climate change is the United Nations Framework Convention on Climate Change (UNFCCC) which defines climate change to be 'a change of climate which is attributed directly or indirectly to human activity that alters the composition of the global atmosphere and which is in addition to natural climate variability observed over comparable time periods' (UNFCCC, 1992, Article 1, Paragraph 2). In summary, the science examines all changes to the climate irrespective of origin while the UN's policy process and measures consider climate change from only human origins.

For this chapter, the scientific definition is adopted, focusing on climate change's effects on climate hazards. While evidence exists for climate change altering non-climaterelated hazards, such as earthquakes and volcanoes (McGuire, 2013), the findings have large uncertainties, so this chapter is confined to climate hazards. Overall, there is no doubt that climate change affects climate hazards, including in Asia. How those hazards are affected involves major complexities, meaning that it would be challenging to give any hierarchy or ranking regarding importance or potential effects. Much depends on the local context.

\section{Zoonotic disease}

Costello et al. (2009) summarise the impacts of climate change on rodent-borne and vector-borne diseases. As temperatures increase, vectors and parasites tend to breed and mature more quickly. More life cycles are permitted within a given timeframe along with an increased rate of biting, each of which supports the spread of vector-borne diseases. In addition to these time factors, vector density over a given area tends to increase with temperature increasing. Meanwhile, vectors are able to survive at higher altitudes and latitudes than before because the climate in the new locations matches the vectors' 
environments in the original locations. Populations living at higher altitudes and latitudes have often never before dealt with these vectors or pathogens, so their immunity and knowledge of countermeasures is minimal.

Costello et al. (2009) particularly highlight mosquito-borne and tick-borne diseases such as malaria, encephalitis, and dengue fever, but their arguments likely apply to many other diseases such as lyme disease, leptospirosis, and West Nile Fever. The authors, though, indicate some climate hazard factors inhibiting vector-borne and rodent-borne diseases due to climate change. Where extreme event frequency or intensity increases, or where the environmental hazards change in nature, vector eggs and larvae could be harmed. Heavy rains can wash away vectors at many life cycle stages. Salinisation of water due to sea-level rise and coastal inundation could inhibit vectors needing freshwater or could force them to move inland or to higher elevations. Consequently, the infectious disease related health impacts of climate change will be highly localised, depending on how specific climate hazards are affected locally_as well as measures taken to deal with disease.

\section{Climate related hazards}

Climate change influences the frequency, severity, location, and characteristics of weather events such as floods, droughts, temperature extremes, and tropical cyclones. The complexities of the interactions between climate change and specific hazards in specific locations sometimes make attribution and projections challenging-again, also because measures taken to deal with the hazards can affect hazard parameters more than climate change.

For tropical cyclones-including for Pacific and Indian Ocean storms-it seems likely that climate change will lead to reduced frequency of formation but increased intensity once a tropical cyclone forms, with large uncertainties in the projections (Knutson et al., 
2010). There are feedbacks amongst sea surface temperatures, stratospheric winds, and the lessening temperature differential between the poles and the tropics (the poles warm faster), in addition to other factors, making analysis challenging. Empirical evidence from around the Pacific collected so far from the Federated States of Micronesia, Kiribati, Tuvalu, and Vanuatu (Ballu et al., 2012; Biribo and Woodroffe, 2013; Rankey, 2011; Webb and Kench, 2010) suggests that it is not inevitable that the low-lying islands will disappear due to sealevel rise. Instead, island responses will vary depending on many factors. In some places, such as Takuu, Papua New Guinea, sea-level rise is already causing inundation and salination problems leading to plans for resettlement.

Precipitation is expected to become much more intense in many locations around the world, including across Asia, due to climate change. Warmer air can hold more moisture meaning that precipitation quantity and intensity can increase. That seems likely to lead to more flooding overall around the world (IPCC, 2013-2014) with regional and seasonal variations. Meanwhile, as sea ice around the Arctic diminishes due to climate change, storms can produce more wave energy, which will likely exacerbate coastal erosion along the Russian Arctic. Melting permafrost will also significantly change the environments of the higher latitudes.

Such complexities impact other hazards and their potential casualties. Increased precipitation under climate change would be expected to increase the frequency and magnitude of landslides, but it is not straightforward. For a landslide, rockslide, mudslide, or other mass movement to occur, there must be material to slide or move. An initial increase in frequency due to climate change has the possibility of using up much of a slope's slideable material, leading to smaller slides in the future because less material can build up before the slide occurs. 


\section{Vulnerability Determining Health Outcomes}

The discussion in the previous section covered the effects of climate change on climate hazards with indications of resultant casualties. This section delves deeper into the latter exploring the root causes and underlying reasons of why casualties occur due to climate hazards. Mortality projections under climate change are provided followed by a description of vulnerability and related concepts. That sets the stage for exploring causal chains from hazard and vulnerability to mortality, using weather, food, farming, and traditional knowledge to illustrate the health impacts.

WHO (2014) estimates global mortality resulting from climate change in 2030 and 2050 via effects from heat, coastal flooding, diarrhoeal disease, malaria, dengue, and undernutrition, all impacts of which will be felt in Asia. That study assumes no major discontinuities in trends; that is, no major societal collapses, wars, or famines, but still estimates 92,781 (with low estimate of 46,314 and a high estimate of 140,100) extra deaths per year from these causes in Asia in 2050, with South Asia hardest hit (WHO, 2014). Aside from hazards not considered such as cold and slides, it is important to examine the assumed causal chain from climate change to climate hazards (discussed above) and then to casualties (discussed here).

Climate hazards alone do not cause injuries and deaths. Vulnerability—the social and political processes that put people and communities in harm's way without adequate resources or options to avoid harm—must be present individually or collectively (Gaillard, 2010; Hewitt, 1983; Lewis, 1999; Wisner et al., 2004, 2012). Meanwhile, resilience processes can reduce casualties and other detrimental health effects, by supporting people and communities in adjusting or adapting to climate hazards and changes in their regimes. Resilience is a highly contested term across many disciplines which has moved away from a basic ecological definition of being able to withstand shocks while maintaining equilibrium 
and much more towards fundamental tenets of disaster risk reduction in terms of being able to build and maintain safe and healthy communities (Alexander, 2013; Lewis and Kelman, 2010; Manyena, 2006; Manyena and Gordon, 2015).

Because so much about vulnerability and resilience is contextual, they are parallel rather than opposite processes, expressing different manifestations of fundamental social and political processes which permit society to deal with hazards-or not. Sometimes, the same action can breed both vulnerability and resilience-often to different sectors of the community. For instance, some groups in Pakistan and Afghanistan oppose girls attending school. School buildings can be made centres for disaster risk reduction and be known in the community as a safe post-disaster location with emergency supplies (Ronan and Johnston, 2006). Where there is gender disparity in school attendance, implementing 'safe schools' programmes could increase boys' resilience, while increasing girls' vulnerability relative to the boys, all to the same flood. Often, the degree in which vulnerability and resilience are present to a specific environmental phenomenon for a specific community group can contribute to determining how hazardous that environmental phenomenon becomes.

Considering river flooding in Bangladesh (Webster et al., 2010) or a heat wave in Seoul such as in 1994 (Kyselý and Kim, 2009), these hazards have long been a feature of life in these places. Some people have been able to cope with them to a certain degree, reducing their vulnerability and increasing their resilience, such as the people living on river islands in Bangladesh where flooding is a way of life (Sarker et al., 2003). Others run into major difficulties, such as those aged over 70 or under 14 in South Korea who were not supported to deal with the heat (Kyselý and Kim, 2009). In Bangladesh, if floods increase in frequency, then the people used to seasonal floods might not be able to deal with the changes without external support—or, as Sarker et al. (2003) imply, increased erosion would be problematic. In Seoul, if the emergency management system and social networks had responded in 1994, 
identifying those who were vulnerable and bringing them to relief centres or providing them with fans and support to pay the electricity bill (amongst other measures), then the death toll would not have been so high. Consequently, even in cases where changes to extreme weather can be directly linked to climate change, the causal pathway to the weather casualties is not clear.

Causal chains are also not straightforward for climate change leading to health impacts due to changes in food/water quality and availability, or due to psychological effects. As average sea level rises, mainly due to the increasing ocean temperature but with contributions from melting ice, water supplies are becoming salinised, also through coastal inundation. Freshwater patterns are changing as well, especially as precipitation and storms change (IPCC, 2013-2014), so the link to water-borne disease can be hard to determine. Regarding food, depending on localised changes, it might be harder or easier to harvest from the land or ocean. Due to a preference for imported food, many Pacific islands currently experience an obesity epidemic leading to non-communicable diseases such as diabetes (Asia Pacific Cohort Studies Collaboration, 2007). If transport costs increase under climate change, then one possible pathway is less dependency on imports leading to improved health conditions, although with the potential for undernutrition if local food resources prove to be inadequate. The tradeoffs and balances are complex with the influence of climate change and climate hazards potentially being small compared to vulnerability of and choices by individuals and communities.

Climate hazards have always been part of farming, including crop and livestock mortality. For example, a review of cotton crop failure linked to farmer suicides in India demonstrated subtle and complex relationships amongst multiple factors (Gruère and Sengupta, 2011) with further concerns about why Indian farmers selected-or were encouraged to select—-specific cotton crops rather than focusing on food crops or a balance 
between subsistence and cash crops. That is important since traditional knowledge systems across Asia have developed over time, and have shown to be adaptable, supporting food security irrespective of climate hazards. Examples are systems for sharing water resources and coordinating agricultural activities, landscape management, and crop diversity (Mohammad, 1992; Moles, 1989).

Those traditional systems did not always prevent disasters, yet they provided a baseline for dealing with environmental changes, variabilities, and trends, permitting flexibility and adaptability—hallmarks of reducing vulnerability and increasing resilience. With climate under climate change projected to move beyond humanity's collective memory, traditional knowledge is becoming less relevant for trying to deal with climate hazards, especially given the major social changes which Asia is also experiencing. Impacts on livelihoods from climate change and climate hazards are inextricably linked with impacts from the undermining of traditional knowledge, changing values, environmental health affected by infrastructure development and pollution, lack of societal interest in supporting people for disaster risk reduction including climate change adaptation, poor social services to support people at risk of suicide, and numerous other vulnerability factors—alongside factors which support resilience such as good governance and education opportunities.

Climate has wide-ranging impacts on health, positive and negative. Decoupling those from other processes-such as choices by those with resources to support or not to support adjustment or adaptation to changing conditions-is not always unambiguous, with chronic vulnerabilities often dominating direct impacts of climate hazards.

\section{Further Case Studies}

This section provides further examples of health impacts of climate hazards in Asia, categorised by hazard (water, temperature, and specific diseases) and by consequence 
(undernutrition and mental health). The discussion cannot be comprehensive on each topic, merely providing some aspects to consider and aiming to meld that with the climate change and vulnerability discussion from the previous two sections.

\section{Water: Storms, Precipitation, Floods, and Droughts}

Flooding, precipitation, and storms lead to casualties through impacts as diverse as drowning; physical trauma from debris; electrocution; increases in faecal-oral, vector-borne, and rodent-borne disease; and loss of livelihoods and shelter (Ahern et al., 2005). Bangladesh is an example of an Asian location affected by flooding, with $70 \%$ of the population living in flood-prone areas, and $26 \%$ at risk from cyclones, although interventions including improved disaster risk reduction and management, storm shelters, and warning systems have demonstrated how much mortality can be reduced (Cash et al., 2013).

Overall, data from South Asian floods show that more women than men tend to die in most types of floods, mainly due to traditions which increase women's vulnerability (for example, Bern et al., 1993; Chowdhury et al., 1993). Women are often not permitted to learn how to swim, might not be permitted to be outside alone, and tend to wear clothes which make it hard to survive in water (taking off their clothes in order to survive would not usually be considered as an option). Women also tend not to get enough to eat, making them undernourished and weaker. Other factors have not been fully studied but are understood to exist, such as the potential fear of sexual violence in evacuation locations or menstruating women not being permitted to be in public areas.

In addition to deaths, injuries, and mental health impacts, water-related hazards can affect environmental health such as by exacerbating endemic disease. Examples from flooding and rainfall were outbreaks of leptospirosis in the Philippines in 2009 (Amilasan et al., 2012) and human fascioliasis in Iran in 1988 and 1999 (Salahi-Moghaddam et al., 2011). 
Health impacts of drought were seen in Iran in 1999-2000 with increases in human skin and eye infections, more animal parasites, and livestock deaths (Salami et al., 2009).

Sea-level rise is expected to affect low-lying coastlines potentially forcing people to move, with Bangladesh and Pacific islands usually named as being the locations most likely to be affected the soonest (IPCC, 2013-2014). Managed evacuation and resettlement can avoid many physical health impacts, but mental health consequences have not been fully investigated, particularly given the extent to which many people are connected to their home and land. In the Pacific, one's identity is closely tied up with one's land and ancestral burial grounds (Ward and Kingdon, 2007). Abandoning that and moving elsewhere, never to return, would not be simple for everyone, even if resettlement were fully resourced. Simultaneously, environmental health is being affected through increased salinisation and changes to ecosystems as new species arrive and some endemic species struggle in the new climate regime.

More widely, water-related hazards affect environmental health across Asia. Too much water, too little water, high winds, salt water, and contaminated water affect the natural and built environments, and their intersections. For instance, mould can build up inside properties, disease vectors can be promoted or inhibited, and ecosystems are rapidly changed. Specific examples range from road dust being transported by sandstorms to Beijing thereby increasing air pollution (Han et al., 2007) through to drinking water source contamination after a cyclone struck Bangladesh (Hoque et al., 1993).

\section{Temperature: Heat and Cold}

Very old and very young people are most affected by heat-related mortality but outdoor exposure, whether agricultural workers in fields or walking kilometres to fetch water, increases impacts. In Japan, the relative risk of mortality in over-65s was estimated to rise to 
1.5 as daily maximum temperatures exceeded optimal temperatures by $20^{\circ} \mathrm{C}$ (Honda et al., 2014). A model for Seoul, Beijing, Tokyo, and Taipei estimated links between air temperature and mortality from respiratory and cardiovascular diseases (Chung et al., 2009).

Mortality and morbidity from heat waves are likely to increase under climate change (Kravchenko et al., 2013). Health impacts from heat stress will depend on physiological adaptation to higher average temperatures as well as living and working conditions. Those with abodes and/or workplaces that do not allow sufficient protection from heat stresstypically the poorest people-will be more affected, as will other vulnerable people including children, the elderly, and people with chronic diseases (Kravchenko et al., 2013).

Productivity, especially related to outdoor work, such as agricultural labour, which is the mainstay for many rural subsistence farmers throughout Asia, will be affected by rising average temperatures and heat extremes. This, in turn, could have knock-on effects for nutrition and other health indicators via impacting local livelihoods for food and water. An empirical study of heat stress in Indian rice farmers estimated a 5\% drop in productivity per $1^{\circ} \mathrm{C}$ increase in heat exposure (Sahu et al., 2013).

Cold extremes have health impacts, such as people dying from lack of warmth as well as influenza being promoted in cold temperatures. In 2007-2008, temperatures in Dushanbe, Tajikistan remained below freezing for over a month, taxing the country's poorly maintained electricity infrastructure; impacting livelihoods as electricity-dependent businesses and factories shut down; promoting disease due to the cold and people living in a single room to keep warm; and leading to other health impacts such as poor sanitation and carbon monoxide poisoning (Kelly, 2012). In all these factors, the climate hazard of cold exacerbated and exposed pre-existing vulnerability conditions rather than being the cause of mortality and morbidity. 


\section{Diarrhoeal Disease}

Although diseases not present in an area before a disaster rarely emerge afterwards, the risk of diarrhoeal disease and other infectious diseases can increase in endemic areas. Reasons include pit latrine overflow; lack of clean water to drink and with which to wash; poor sanitation facilities and lack of personal hygiene after evacuating; overcrowding so that people are in close proximity to one another; insufficient food and cooking apparatus; and lack of access to health services (which may have collapsed) including vaccination (Kouadio et al., 2012).

Diarrhoeal disease is projected to increase in Asia in the short-term with rising temperatures under climate change, by an estimated $3-10 \%$ per $1^{\circ} \mathrm{C}$ temperature rise (WHO, 2014). Nonetheless, even under low socio-economic growth scenarios and with the temperature increases due to climate change, diarrhoeal disease in Asia is projected to be lower in 2050 than in 2030, primarily due to assumed improvements in water, sanitation, and public health provision (WHO, 2014). These projections again assume no major discontinuities in trends, but illustrate that complicated interactions amongst many factors can sometimes lessen the consequences climate hazards could have.

\section{Malaria and Dengue}

Flooding and heavy rains-via the stagnant water mosquito breeding grounds left behind and population displacement from non-endemic to endemic areas-and increasing temperatures (see Costello et al., 2009) can increase risk of malaria and dengue fever in Asia (Kouadio et al., 2012; WHO, 2014), balanced with the factors noted above which wash away larvae or inhibit mosquito breeding. In fact, sometimes mosquitoes are not a problem the first few days after a tropical cyclone, which leaves some time to implement prevention measures before they return. 
Malaria transmission requires ambient temperatures of at least $16^{\circ} \mathrm{C}$ and appears to be optimal at $28-30^{\circ} \mathrm{C}$, similar to the transmission of dengue; while mosquito survival declines above $35^{\circ} \mathrm{C}$ and is not usually possible at $40^{\circ} \mathrm{C}$ (WHO, 2014). Nonetheless, increasing temperatures could result in adaptation and survival of the vector and parasite at higher temperatures (Caminade et al., 2014). Historically, malaria transmission and consequent morbidity and mortality have decreased as socioeconomic conditions improve; indeed, malaria-type diseases were eradicated in Europe and North America. Nevertheless, despite expected improvements in socio-economic conditions across Asia, WHO (2014) estimates that increased average ambient temperatures resulting from climate change will lead to more than an additional 200 million people being at risk of malaria in South and South-east Asia in coming decades, with an even higher number at risk due to population increases.

Dengue fever is also affected through increased risk due to population growth and decreased risk due to socioeconomic conditions improving in Asia, including piped water reducing use of the water storage containers in which dengue-carrying $A$. aegypti mosquitoes typically breed (WHO, 2014). Increases in temperature and precipitation due to climate change in Asia are still expected to increase the number of people at risk of dengue fever overall (WHO, 2014).

\section{Undernutrition}

Undernutrition is ultimately caused by a lack of calories but has complex, underlying causes related to the production, availability, and access to food. Hence, it is linked to poverty, trade, water, and sanitation since diarrhoeal disease exacerbates undernutrition. Undernutrition is tackled, amongst other actions, through women's education and empowerment such as knowledge of diets for children and ability to feed children properly 
(WHO, 2014). Undernourished children are more vulnerable to infectious diseases and other health problems including poor physical and cognitive development (Black et al., 2008).

Climate change is likely to adversely affect crop production, particularly in seasonally dry and low-latitude regions due to warming and a changing regime of climate hazards, while sea-level rise could salinise lands, making it necessary to change crops entirely (IPCC, 20132014; WHO, 2014). East Asia has already seen impacts on food production systems and food security including through rice yields, vegetables, fruit, and livestock. Attribution of observed crop, livestock, food, and water trends directly to climate change is complex, especially given poorly understood responses of crops to increasing atmospheric carbon dioxide concentrations and the positive effects of adaptation measures (IPCC, 2013-2014). Meanwhile, although any conclusions are tenuous, more northern latitudes in Asia might experience productivity increases due to longer growing seasons and warming temperatures.

Models (WHO, 2014; Lloyd et al., 2011) estimate that, in South Asia in 2030, the effects of climate change on crop production, global food trade, and consequent national calorie availability and distribution will yield an additional 1,100,000 children under the age of five who are moderately stunted and 900,000 who are severely stunted, with approximately 20,000 children dying from this malnutrition. South Asia has higher mortality relative to the number of cases of undernutrition due to additional vulnerabilities related to poverty and inadequate food distribution, indicating that climate hazards and the effects of climate change are only one factor amongst many.

\section{Mental Health Impacts}

There has been limited empirical research to date, especially in Asia, on the impact of climate change on mental health. A review by Bourque and Willox (2014) suggests that climate change could increase psychological distress, depression, and anxiety as well as 
addiction and suicide rates, especially for those already vulnerable and those with preexisting mental health conditions. Again, the key is vulnerability and pre-existing conditions, with climate hazards influencing existing problems but not necessarily causing completely new difficulties.

Environmental changes are already occurring rapidly in some areas such as the Arctic, namely northern Russia, and high altitudes, especially the Himalayas, with expected major mental health consequences for those dependent on natural resource based livelihoods. A study from Bangladesh which was able to sample 162 children who had been assessed six months before a flood and five months afterwards found an increase from zero to almost $10 \%$ in aggressive behaviour and also that $34 \%$ of 134 children who did not wet their bed before, now did (Durkin et al., 1993). The authors consider these symptoms to be 'post-traumatic stress' and attribute them to the flood. Ahern et al. (2005) document increased anxiety, depression, and post-traumatic stress disorder from floods from several other studies, although they found no evidence for an increase in suicides. Conversely, if rates of flooding increase, then inundation might become a regular part of life, rather than being unusual and extreme, thereby decreasing adverse mental health impacts.

In addition to direct effects on mental health, the impact of climate hazards can exacerbate mental health problems by disrupting or stopping access to mental health services where they exist (Bourque and Willox, 2014).

\section{Agenda for Research and Action}

From the above discussion, specific topics emerge as being prominent in a research and action agenda regarding climate hazards, health, and Asia. Six main suggestions are provided here. 
1. Climate change as a hazard driver, enhancer, or diminisher, rather than as a cause of health impacts itself.

Climate change in itself does not cause health impacts, but human failure to respond to climate change and its consequences does. To develop and enact effective policies for Asia, it is important to move beyond the rhetoric of climate change as a direct cause and, instead, to understand better the causal sequence of climate change altering environmental hazards, cycles, trends, processes, and conditions, which in turn can expose already existing vulnerabilities and resiliences, yielding positive and negative health impacts. Given the complexity of this causal chain and the large environmental differences in Asia-consider, for instance, megacity, desert, mountain, forest, and atoll contexts-more research is needed to explore the causal chain for specific contexts and to build up a repertoire of comparative analyses from which general lessons and transferability/non-transferability options could be explored.

2. Causes and circumstances of individual morbidity and mortality.

Large gaps exist in understanding who is physically affected by climate hazards, how they are affected, and why their vulnerability is not addressed leading to death or injury in specific hazard instances. This is particularly the case in Asia where disaster deaths can be reported in the hundreds or tens of thousands with limited scope to investigate and explain each death on an individual basis, as has been completed for floods in Europe and the U.S.A. (for example, Jonkman and Kelman, 2005) amongst others.

An additional challenge is that disaster mortality studies tend to focus on people whose death is clearly linked to a specific hazard, often looking at hazard as the only cause of death because such data are relatively unambiguous and comparatively easy to collect. Yet many deaths occur months or years after a specific hazard manifested or had multiple inputs 
into the death. The cause might be physical, for example someone in a coma who was not evacuated, but is often mental, due to stress, lack of post-disaster support, or lack of financial or social resources to cope with difficulties. Because establishing cause and effect in such cases is challenging, these deaths frequently remain unnoticed and uncounted, becoming part of a disaster's hidden cost (see also point 4).

3. Improvements in mapping out and modelling cause and consequence pathways amongst hazards, vulnerabilities, and health outcomes.

At the first order, hazard and vulnerability are generally considered to be independent variables, but that neglects the interactions amongst them. For example, people living in a hilly region in Bhutan experiencing a cold snap might not be able to afford increased electricity costs_-or might not have electricity—so their vulnerability to cold forces them to cut down trees for burning. That amplifies the likelihood and intensity of flood and slide parameters, exposing them later to worsening climate hazards. Better understanding of the interactions and feedbacks can contribute to developing policy and practice which reduces vulnerabilities and improves health without exacerbating hazards.

4. Mental health impacts.

Studies of mental health impacts of climate hazards are few for Asia, yet this topic is essential for gaining a full picture of climate hazards and health. That relates to the psychological effects of specific climate hazards and responses to them, but can also be connected to climate change more directly. In places such as high-altitude communities and low-elevation coastal communities, the changing environment means that traditional knowledge is already becoming outdated to some degree, as seasons and biota shift. The psychological effects include the loss of an anchor connecting community with environment 
as well as, in places, lack of understanding of why it is harder to provide food and livelihoods from the environment. If migration is required, then the loss of identity, culture, and language, alongside the disorientation of moving from a place which might rarely have been left before, could be psychologically devastating. Such studies for Asia have rarely been conducted, but are starting to emerge for island and mountain communities, although they require wider scope.

5. Environmental health impacts.

The interplay between environmental health and human health is understudied, from nomadic pastoralists in Mongolia dealing with shifting seasons through to pollution and proximity to waste management sites in urban settings. For Asia, little work connects or integrates environmental health indicators, community health indicators, and individual health indicators. With the advent of ecosystem-based adaptation as a process for dealing with climate change, although noting that it is not different from ecosystem-based management, more work regarding environmental health impacts of climate change is expected and needed. Tackling this topic would also contribute to expanding the understanding and implementation of health interventions, by ensuring that these responses do not highlight only humans, but also factor in community surroundings including the built and natural environments.

6. Evaluate the reliability, validity and sustainability of new knowledge forms and their combinations.

Despite social and environmental changes across Asia, traditional knowledge, local knowledge, vernacular knowledge, and indigenous knowledge have rich contributions to make for improving health and for reducing vulnerability and building resilience in the face 
of climate hazards. These knowledge forms can be combined with external knowledge forms (see one framework in Mercer et al., 2010) such as science and professions providing remote sensed data, engineering analyses, historical interpretations, and focus group data amongst many others. Analytical and conceptual models can be improved without relying exclusively on different forms of modelling, while new approaches for collecting quantitative and qualitative data can be developed, tested, and applied.

Many challenges face Asia with respect to climate change and health. These challenges can become opportunities to reduce current vulnerabilities and to build resilience, including beyond climate; to improve the current state of human, community, and environmental health; and to prepare Asia and the world for the changes to hazards expected under climate change. The key messages are the complexities of the interactions, the balance amongst positive and negative outcomes, and the difficulties with assuming specific causal lines.

Those messages are illustrated by the main points of climate change influencing zoonotic and other infectious diseases along with climate related hazards, although causality from climate change to health outcomes is not straightforward. Instead, vulnerabilities determine health outcomes with much being contextual, such as the efforts which have been put into building resilience, implementing disaster risk reduction processes including climate change adaptation, and supporting food, water, and livelihood security. Decoupling climate change effects from all other processes is not easy, with undernutrition, mental health, and environmental health demonstrating the interactions.

Providing relative magnitudes of importance or providing a hierarchy of concern for all these topics encounters credibility concerns for two reasons. First, data have often not yet been collected whilst projections have large uncertainties. Second, the importance usually 
depends on context. For instance, what applies to Phnom Penh might not apply to Siem Reap, Cambodia, Southeast Asia, or the entire continent. These concerns are not a call to avoid general lessons and messages, as those have been provided here. Instead, it is important to accept that sometimes qualitative descriptions can provide the most robust ways forward.

Ultimately, climate change is only one factor amongst many regarding health, vulnerability, and development, with it frequently not dominating. Where climate change ranks compared to other concerns is contextual, often with measures taken to deal with climate change and other concerns being more important than the projections for climate change impacts. Rather than highlighting climate change, by tackling vulnerability overall it is possible for good health outcomes to emerge, irrespective of how the climate changes.

\section{References}

Ahern, M., Kovats, R.S., Wilkinson, P., Few, R., and Matthies, F., 2005. Global Health Impacts of Floods: Epidemiologic Evidence. Epidemiologic Reviews, 27, pp.36-46.

Alexander, D.E., 2013. Resilience and disaster risk reduction: an etymological journey. Natural Hazards and Earth Systems Sciences, 13: pp.2707-2716.

Amilasan, A.T., Ujiie, M., Suzuki, M., Salva, E., Belo, M.C.P., Koizumi, N., Yoshimatsu, K., Schmidt, W.P., Marte, S., Dimaano, E.M., Villarama, J.B., and Ariyoshi, K., 2012. Outbreak of Leptospirosis after Flood, the Philippines, 2009. Emerging Infectious Diseases, 18, pp.91-4.

Asia Pacific Cohort Studies Collaboration, 2007. The burden of overweight and obesity in the Asia-Pacific region. Obesity Reviews, 8(3), pp.191-6.

Ballu, V., Bouin, M.N., Siméoni, P., Crawford, W.C., Calmant, S., Boré, J.M., Kanas, T., and Pelletier, B., 2012. Comparing the role of absolute sea-level rise and vertical tectonic 
motions in coastal flooding, Torres Islands (Vanuatu). Proceedings of the National Academy of Sciences USA, 108, pp.13019-22.

Bern, C., Sniezek, J., Mathbor, G.M., Siddiqi, M.S., Ronsmans, C., Chowdhury, A.M., Choudhury, A.E., Islam, K., Bennish, M., Noji, E., and Glass, R.I., 1993. Risk factors for mortality in the Bangladesh cyclone of 1991. Bulletin of the World Health Organization, 71(1), pp.73-8.

Biribo, N. and Woodroffe, C.D., 2013. Historical area and shoreline change of reef islands around Tarawa Atoll, Kiribati. Sustainability Science, 8, pp.345-362.

Black, R.E., Allen, L.H., Bhutta, Z.A., Caulfield, L.E., de Onis, M., Ezzati, M., Mathers, C., and Rivera, J., for the Maternal and Child Undernutrition Study Group, 2008. Maternal and child undernutrition: global and regional exposures and health consequences. Lancet, 371, pp.243-60.

Bourque, F. and Willox A.C., 2014. Climate change: The next challenge for public mental health. International Review of Psychiatry, 26, pp.415-22.

Cai, S., Chan, N.W., Kung, H.-t., and Liu, P.-S., 2001. Management of flood disasters in the Jianghan Plain, China. Disaster Prevention and Management, 10(5), pp.339-48.

Caminade, C., Kovats, S., Rocklov, J., Tompkins, A.M., Morse, A.P., Colón-González, F.J., Stenlund, H., Martens, P., and Lloyd, S.J., 2014. Impact of climate change on global malaria distribution. Proceedings of the National Academy of Sciences of the United States of America, 111, pp.3286-91.

Cash, R.A., Halder, S.R., Husain, M., Islam, M.S., Mallick, F.H., May, M.A., Rahman, M., and Rahman, M.A., 2013. Reducing the health effect of natural hazards in Bangladesh. Lancet, 382, pp.2094-103

Chowdhury, A.M.R., Bhuyia, A.U., Choudhury, A.Y., and Sen, R., 1993. The Bangladesh Cyclone of 1991: Why So Many People Died. Disasters, 17(4), pp.291-304. 
Chung, J.-Y., Honda, Y., Hong, Y.-C., Pan, X.-C., Guo, Y.-L., and Kim, H., 2009. Ambient temperature and mortality: An international study in four capital cities of East Asia. Science of The Total Environment, 408(2), 390-6.

Costello, A., Abbas, M., Allen, A., Ball, S., Bell, S., Bellamy, R., Friel, S., Groce, N., Johnson, A., Kett, M., Lee, M., Levy, C., Maslin, M., McCoy, D., McGuire, B., Montgomery, H., Napier, D., Pagel, C., Patel, J., Antonio, J., de Oliveira, P., Redclift, N., Rees, H., Rogger, D., Scott, J., Stephenson, J., Twigg, J., Wolff, J., and Patterson, C., 2009. Managing the health effects of climate change. Lancet, 373, pp.1693-733.

Durkin, M.S., Khan, N., Davidson, L.L., Zaman, S.S., and Stein, Z.A., 1993. The effects of a natural disaster on child behaviour: evidence for post-traumatic stress. American Journal of Public Health, 83, pp.1549-53.

Gaillard, JC, 2010. Vulnerability, Capacity, and Resilience: Perspectives for Climate and Disaster Risk Reduction. Journal of International Development, 22(2), pp.218-232.

Gruère, G. and Sengupta, D., 2011. Bt Cotton and Farmer Suicides in India: An Evidencebased Assessment. Journal of Development Studies, 47(2), 316-37.

Han, L., Zhuang, G., Chenga, S., Wang, Y., and Li, J., 2007. Characteristics of re-suspended road dust and its impact on the atmospheric environment in Beijing. Atmospheric Environment, 41(35), 7485-99.

Hewitt, K. ed., 1983. Interpretations of Calamity from the Viewpoint of Human Ecology. London: Allen \& Unwin.

Honda, Y., Kondo, M., McGregor, G., Kim, H., Guo, Y.-L., Hijioka, Y., Yoshikawa, M., Oka, K., Takano, S., Hales, S., and Kovats, R.S., 2014. Heat-related mortality risk model for climate change impact projection. Environmental Health and Preventive Medicine, 19, pp.56-63. 
Hoque, B.A., Sack, R.B., Jahangir, A.M., Hazera, N., Siddiqi, M., and Nahid, A., 1993. Environmental Health and the 1991 Bangladesh Cyclone. Disasters, 17(2), pp.143-52. IPCC, 2013-2014. Fifth Assessment Report. Geneva: IPCC (Intergovernmental Panel on Climate Change).

Jain, S.K., Lohani, A.K., Singh, R.D., Chaudhary, A., and Thakural, L.N., 2012. Glacial lakes and glacial lake outburst flood in a Himalayan basin using remote sensing and GIS. Natural Hazards, 62(3), pp. 887-99.

Jayasekara, R.S. and Schultz, T., 2007. Health status, trends, and issues in Sri Lanka. Nursing and Health Sciences, 9, pp.228-33.

Jonkman, S.N. and Kelman, I., 2005. An Analysis of Causes and Circumstances of Flood Disaster Deaths. Disasters, 29, pp.75-97.

Kelly, C., 2012. Cold extremes in Tajikistan. In: B. Wisner, JC Gaillard, and I. Kelman, eds. Handbook of Hazards and Disaster Risk Reduction. Abingdon: Routledge, p.276.

Knutson, T.R., McBride, J.L., Chan, J., Emanuel, K., Holland, G., Landsea, C., Held, I., Kossin, J.P., Srivastava, A.K., and Sugi, M., 2010. Tropical cyclones and climate change. Nature Geoscience, 3, pp.157-63.

Kouadio, I.K., Aljunid, S., Kamigaki, T., Hammad, K., and Oshitani, H., 2012. Infectious disease following natural disasters: prevention and control measures. Expert Review of Anti-infective Therapy, 10, pp.95-104.

Kravchenko, J., Abernethy, A.P., Fawzy, M., and Lyerly, H.K., 2013. Minimization of Heatwave Morbidity and Mortality. American Journal of Preventive Medicine, 44, pp.274-82.

Kyselý, J. and Kim, J., 2009. Mortality during heat waves in South Korea, 1991 to 2005: How exceptional was the 1994 heat wave? Climate Research, 38(2), pp.105-16. 
Lewis, J., 1999. Development in Disaster-prone Places: Studies of Vulnerability. London: Intermediate Technology Publications.

Lewis, J. and Kelman, I., 2010. Places, People and Perpetuity: Community Capacities in Ecologies of Catastrophe. ACME: An International E-Journal for Critical Geographies, 9, pp.191-220.

Lloyd, S.J., Kovats, R.S., and Chalabi, Z., 2011. Climate Change, Crop Yields, and Undernutrition: Development of a Model to Quantify the Impact of Climate Scenarios on Child Undernutrition. Environmental Health Perspectives, 119, pp.1817-23.

McGuire, B., 2013. Waking the Giant: How a Changing Climate Triggers Earthquakes, Tsunamis, and Volcanoes. Oxford: Oxford University Press.

Manyena, S.B., 2006. The concept of resilience revisited. Disasters, 30: pp.433-450.

Manyena, S.B., and Gordon, S., 2015. Bridging the concepts of resilience, fragility and stabilisation. Disaster Prevention and Management, 24(1), forthcoming.

Mercer, J., Kelman, I., Taranis, L., and Suchet, S., 2010. Framework for Integrating Indigenous and Scientific Knowledge for Disaster Risk Reduction. Disasters, 34(1), pp.214-39.

Mohammad, N. ed., 1992. Dynamics of Agricultural Development. New Delhi: Concept.

Moles, J.A., 1989. Agricultural Sustainability and Traditional Agriculture: Learning from the Past and its Relevance to Sri Lanka. Human Organization, 48(1), pp.70-8.

Paul, B.K., 1998. Coping with the 1996 Tornado in Tangail, Bangladesh: An Analysis of Field Data. The Professional Geographer, 50(3), pp.287-301.

Rankey, E.C., 2011. Nature and stability of atoll island shorelines: Gilbert Island chain, Kiribati, equatorial Pacific. Sedimentology, 58, pp.1831-59.

Ronan, K. and Johnston, D. 2006. Promoting Community Resilience in Disasters: The Role for Schools, Youth, and Families. Springer: New York. 
Sahu, S., Sett, M., and Kjellstrom, T., 2013. Heat Exposure, Cardiovascular Stress and Work Productivity in Rice Harvesters in India: Implications for a Climate Change Future. Industrial Health, 51, pp.424-31.

Salahi-Moghaddam, A., Habibi-Nokhandam, M., and Fuentes, M.V., 2011. Low-altitude outbreaks of human fascioliasis related with summer rainfall in Gilan province, Iran. Geospatial Health, 6, pp.133-6.

Salami, H., Shahnooshi, N., and Thomson, K.J., 2009. The economic impacts of drought on the economy of Iran: An integration of linear programming and macroeconometric modelling approaches. Ecological Economics, 68(4), pp.1032-9.

Sarker, M.H., Huque, I., Alam, M., and Koudstaal, R., 2003. Rivers, chars and char dwellers of Bangladesh. International Journal of River Basin Management, 1(1), pp.61-80.

UNFCCC, 1992. United Nations Framework Convention on Climate Change. Bonn: UNFCCC (United Nations Framework Convention on Climate Change).

Walmsley, J., 2006. The nature of community: putting community in place. Dialogue, 25, pp.5-12.

Ward, R.G. and Kingdon, E., 2007. Land, Custom and Practice in the South Pacific. Cambridge: Cambridge University Press.

Webb, A.P. and Kench, P.S., 2010. The dynamic response of reef islands to sea-level rise: evidence from multi-decadal analysis of island change in the Central Pacific. Global and Planetary Change, 72, pp.234-46.

Webster, P.J., Jian, J., Hopson, T.M., Hoyos, C.D., Agudelo, P.A., Chang, H.R., Curry, J.A., Grossman, R.L., Palmer, T.N., and Subbiah, A.R., 2010. Extended-Range Probabilistic Forecasts of Ganges and Brahmaputra Floods in Bangladesh. Bulletin of the American Meteorological Society, 91, pp.1493-514. 
WHO, 1946. Preamble to the Constitution of the World Health Organization as adopted by the International Health Conference, New York, 19-22 June, 1946; signed on 22 July 1946 by the representatives of 61 States (Official Records of the World Health Organization, no. 2, p. 100) and entered into force on 7 April 1948.

WHO, 2014. Quantitative risk assessment of the effects of climate change on selected causes of death, 2030s and 2050s. Geneva: World Health Organisation.

WHO, 2015. Environmental Health. Geneva: World Health Organisation, http://www.who.int/topics/environmental_health/en accessed 5 January 2015.

Wisner, B., Blaikie, P., Cannon, T., and Davis, I., 2004. At Risk: Natural Hazards, People's Vulnerability and Disasters, 2nd ed. London: Routledge.

Wisner, B., Gaillard, JC, and Kelman, I. eds., 2012. Handbook of Hazards and Disaster Risk Reduction. Abingdon: Routledge.

\section{Further readings}

Akhtar, R. and Kovats, S., 2008. Climate, climate change and human health in Asian cities. Environment and Urbanization, 20(1), pp.165-75.

Campbell-Lendrum, D. and Corvalán, C., 2007. Climate Change and Developing-Country Cities: Implications For Environmental Health and Equity. Journal of Urban Health, 84(1)Supplement, pp.109-17.

Forman, S., Hungerford, N., Yamakawa, M., Yanase, T., Tsai, H.J., Joo, Y.S., Yang, D.K., and Nha, J.J., 2008. Climate change impacts and risks for animal health in Asia. Revue scientifique et technique, 27(2), pp.581-97.

Haines, A., and Patz, J.A., 2004. Health Effects of Climate Change. JAMA: The Journal of the American Medical Association, 291(1): pp.99-103. 
Mol, L. and Sternberg, T. eds., Changing Deserts: Integrating People and their Environment. Cambridge: White Horse Press.

Woodward, A., Hales, S., and Weinstein, P., 1998. Climate change and human health in the Asia Pacific region: who will be most vulnerable? Climate Research, 11, pp.31-8. 